\title{
Article
}

\section{Zone-Dependent Architecture and Biochemical Composition of Decellularized Porcine Nasal Cartilage Modulate the Activity of Adipose Tissue-Derived Stem Cells in Cartilage Regeneration}

\author{
Constanze Kuhlmann ${ }^{1,2}{ }^{\oplus}$, Thilo L. Schenck ${ }^{1}$, Attila Aszodi ${ }^{2}{ }^{\oplus}$, Riccardo E. Giunta ${ }^{1}$ \\ and Paul Severin Wiggenhauser $1, * \mathbb{B}$ \\ 1 Department of Hand, Plastic and Aesthetic Surgery, LMU Klinikum, University Hospital, LMU Munich, \\ Ziemsenstrasse 5, 80336 Munich, Germany; constanze.kuhlmann@med.uni-muenchen.de (C.K.); \\ Thilo.schenck@med.uni-muenchen.de (T.L.S.); riccardo.giunta@med.uni-muenchen.de (R.E.G.) \\ 2 Laboratory of Cartilage Development, Diseases and Regeneration, Department for Orthopaedics and Trauma \\ Surgery, Musculoskeletal University Center Munich (MUM), University Hospital, LMU Munich, \\ Fraunhoferstrasse 20, 82152 Planegg, Germany; Attila.aszodi@med.uni-muenchen.de \\ * Correspondence: severin.wiggenhauser@med.uni-muenchen.de
}

check for updates

Citation: Kuhlmann, C.; Schenck, T.L.; Aszodi, A.; Giunta, R.E.; Wiggenhauser, P.S. Zone-Dependent Architecture and Biochemical Composition of Decellularized Porcine Nasal Cartilage Modulate the Activity of Adipose Tissue-Derived Stem Cells in Cartilage Regeneration. Int. J. Mol. Sci. 2021, 22, 9917. https://doi.org/10.3390/ijms22189917

Academic Editor: Alain Chapel

Received: 30 July 2021

Accepted: 3 September 2021

Published: 14 September 2021

Publisher's Note: MDPI stays neutral with regard to jurisdictional claims in published maps and institutional affiliations.

Copyright: (c) 2021 by the authors. Licensee MDPI, Basel, Switzerland. This article is an open access article distributed under the terms and conditions of the Creative Commons Attribution (CC BY) license (https:/ / creativecommons.org/licenses/by/ $4.0 /)$.

\begin{abstract}
Previous anatomical studies have shown different functional zones in human nasal septal cartilage (NC). These zones differ in respect to histological architecture and biochemical composition. The aim of this study was to investigate the influence of these zones on the fate of stem cells from a regenerative perspective. Therefore, decellularized porcine septal cartilage was prepared and subjected to histological assessment to demonstrate its equivalence to human cartilage. Decellularized porcine NC (DPNC) exposed distinct surfaces depending on two different histological zones: the outer surface (OS), which is equivalent to the superficial zone, and the inner surface (IS), which is equivalent to the central zone. Human adipose tissue-derived stem cells (ASCs) were isolated from the abdominal fat tissue of five female patients and were seeded on the IS and OS of DPNC, respectively. Cell seeding efficiency (CSE), vitality, proliferation, migration, the production of sulfated glycosaminoglycans (sGAG) and chondrogenic differentiation capacity were evaluated by histological staining (DAPI, Phalloidin, Live-Dead), biochemical assays (alamarBlue ${ }^{\circledR}$, PicoGreen $\left.^{\circledR}, \mathrm{DMMB}\right)$ and the quantification of gene expression (qPCR). Results show that cell vitality and CSE were not influenced by DPNC zones. ASCs, however, showed a significantly higher proliferation and elevated expression of early chondrogenic differentiation, as well as fibrocartilage markers, on the OS. On the contrary, there was a significantly higher upregulation of hypertrophy marker MMP13 $(p<0.0001)$ and GAG production ( $p=0.0105$ ) on the IS, whereas cell invasion into the three-dimensional DPNC was higher in comparison to the OS. We conclude that the zonal-dependent distinct architecture and composition of NC modulates activities of ASCs seeded on DPNC. These findings might be used for engineering of cartilage substitutes needed in facial reconstructive surgery that yield an equivalent histological and functional structure, such as native NC.
\end{abstract}

Keywords: cell-matrix interaction; tissue engineering; adipose tissue-derived stem cells; ASCs; nasal septal cartilage regeneration; stem cell fate; biomimicry; extracellular matrix zone

\section{Introduction}

The destruction of nasal septal cartilage due to trauma, skin cancer surgery, autoimmune disease or infection can lead to various problems, including impaired breathing, smelling disorders and obvious cosmetic deformity [1-4]. The surgical repair of those defects often requires costal or auricular cartilage to reconstruct nasal septal cartilage (NC). However, the harvesting of autologous cartilage bears the risk of donor site morbidity $[1,5,6]$. Those complications could be avoided if a viable, biocompatible and biomimetic equivalent to NC were available [7]. Hence, tissue engineering approaches aim to produce cartilage tissue satisfying surgical needs [8,9]. 
The most common cell sources for cartilage tissue engineering are either mature chondrocytes or adult mesenchymal stem cells (MSCs), e.g., found in adipose tissue $[10,11]$. The so called adipose tissue-derived stem cells (ASCs) are an ideal candidate for tissue engineering tasks [10]. Firstly, they are easily accessible through liposuction and are almost abundantly available, especially in contrast to human nasal and articular chondrocytes $[12,13]$. Secondly, as stem cells, they have not designated to a specific cell line yet and are able to differentiate into chondrocytes [14-16]. The chondrogenesis of MSCs proceeds over three intermediate steps, with a hypertrophic chondrocyte as a terminal differentiation endpoint $[17,18]$. Stem cells evolve via chondroprogenitors to chondroblasts and mature to chondrocytes. This complex process is accompanied by the genetic regulation of chondrogenic markers and secretion of specific extracellular matrix (ECM)-proteins, such as collagen type II and aggrecan $[17,18]$. ASCs are naturally found in the so-called stem cell niche of adipose tissue, where they reside in a quiescent state until they are activated by environmental cues, leading to proliferation or differentiation [19-21].

Artificial polymers or composite materials derived from decellularized tissue play an eminent role in current tissue engineering approaches. Recent studies also investigated xenogenic cartilage, e.g., decellularized porcine nasal septal cartilage (DPNC), as a substitute of human cartilage when decellularized ECM was chosen in the specific approach $[10,22]$. The decellularization process removes all native chondrocytes and pathogens, while simultaneously increasing the matrix porosity to allow for a more sufficient recellularization [23]. Decellularized cartilage has the advantage of providing a high degree of biomimicry due to its composition and three-dimensional architecture derived from native cartilage $[10,24]$. Previous experiments have shown that DPNC yields a proper environment for human nasal chondrocytes and ASCs that enables cartilage regeneration $[23,25-27]$.

Furthermore, cell-matrix interactions play an important role in cell regulation and stem cell differentiation [28,29]. Gattazo et al. described ECM as a complex and dynamic environment that has the ability to influence and regulate cell behavior, owing to its biochemical, biophysical and biomechanical properties [30]. Biochemical communication between cells and the matrix is mediated by cell surface proteins and growth factors via direct or indirect signaling pathways [31]. The biophysical properties of ECM comprise matrix porosity, rigidity and insolubility and regulation of anchorage-related functions, such as cell division and migration [28]. The biomechanical cell-matrix interaction describes the transmission of external forces from ECM to the cell, leading to changes in cell morphology and behavior [32,33]. This process is known as mechanotransduction and is primarily conveyed by integrins [34]. A vivid example of the biophysical interaction between cells and ECM in cartilage is the circumstance that chondrocytes tend to dedifferentiate in a two-dimensional (2D) environment and start to express a spindle-shaped phenotype [35]. Dedifferentiation is accompanied by the downregulation of cartilagespecific gene expression (e.g., collagen type 2 alpha 1 (COL2A1) and aggrecan (ACAN)) and reduced ECM secretion, whereas the expression of the fibroblast marker, collagen type I (COL1A1), is upregulated [36]. This process could be reversed if cells are cultivated in a three-dimensional (3D) environment [35,37]. The ECM that directly surrounds a cell is described as a pericellular matrix (PCM) [38]. The PCM was identified as the main ECM compartment for the cell-matrix interaction, with the ability to specify the lineage of stem cells and contribute to resulting phenotypes [38-40].

Cartilage tissue architecture is intimately linked to its biochemical and biomechanical functions, which are determined by a well-balanced composition of cells and macromolecules. On the one side, there are glycosaminoglycans (GAGs) that bind water through ionic forces and lead to the typical swelling pressure of cartilage, and, on the other side, there are different types of collagens interwoven to a well described network that withstand the swelling pressure of GAGs and give support to the three-dimensional shape of the specific cartilage. Interspersed in a typical manner, chondrocytes are located within this mechanoresponsive and mechanotransducive network of the extracellular matrix. Keeping 
this in mind, histological evaluation of the human NC revealed three different zones within the cartilage that all possess a distinct histological architecture with a typical interplay of the extracellular matrix and cells: a superficial, intermediate and central zone [41,42]. The anatomical organization of cells and the matrix varies in between these zones. The superficial zone contains chondrocytes that express a proliferative phenotype: they are numerous, flat, small and are surrounded by dense collagen type II deposits [43]. Towards the central zone, the cell phenotype becomes more hypertrophic, spheroidal and aligned in columns within deeper layers of cartilage [41,42]. The intermediate zone appears to be a transitional zone, whereas cells of the central zone express the most differentiated phenotype, with comparably sparse collagen type II deposits in their environment. GAG and cartilage oligomeric matrix protein (COMP), as non-collagenous matrix components, are distributed more intensely and homogenously in the superficial zone, whereas they are mainly found in the direct surroundings of chondrocytes in the central zone of the nasal septal cartilage [42,43].

In this study, we hypothesize that the NC zones have distinct functions by promoting proliferation and terminal differentiation in the superficial zone and the central zone, respectively. Applying a tissue engineering approach, we suppose that ASCs that were cultured on DPNC might be influenced differently by cell-matrix interactions, depending on the specific zone the ECM was taken from. Thus, ASCs might become more proliferative and less differentiated if exposed to superficial zones when compared to ASCs exposed to central zones.

\section{Results}

\subsection{Histological Analysis of Native Nasal Cartilage}

Histological sections of porcine and human nasal cartilage demonstrated a similar zonal architecture, according to cellular alignment (Figure 1). Alcian blue staining and collagen type II immunostaining were found to be homogenous within the entire samples. In contrast to human cartilage, a shorter intermediate zone was detectable between the superficial and central zones in porcine cartilage.

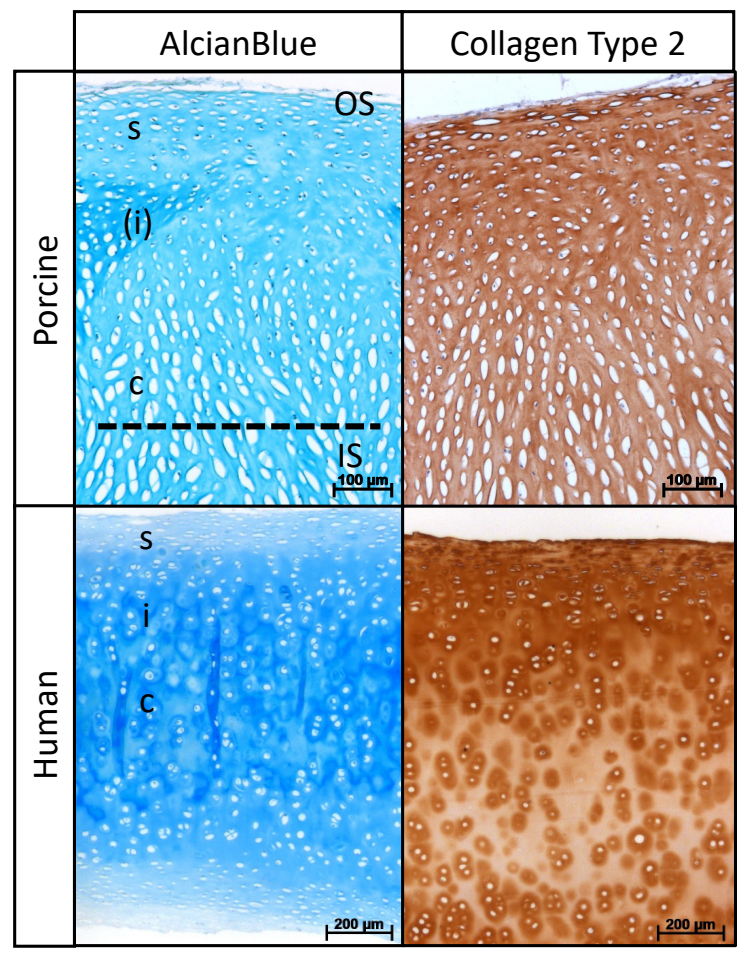

Figure 1. Histological organization of DPNC. Porcine and human nasal cartilage show similar zonal 
architecture: superficial (s), intermediate (i) and central (c) zone. Note less distinct intermediate zone in porcine cartilage marked by (i). Dotted line shows the cutting plane during preparation of scaffolds. OS identifies area of seeding on outer surface and IS on inner surface.

\subsection{Evaluation of Seeding Success, Cell Distribution and Cell Vitality on DPNC Surfaces}

The Live-Dead (LD) assay and fluorescence imaging indicated the successful seeding of ASC s on both IS and OS surfaces of the DPNC. ASCs adhered and aligned similarly on both zones (Figure 2). There was no obvious difference regarding the cell vitality and distribution between OS and IS $24 \mathrm{~h}$ after seeding. The number of dead cells, represented by red PI staining, was comparably low on both scaffold surfaces. The calculated cell seeding efficiencies (CSE) were similar on both DPNC surfaces and showed no statistically significant difference $(p=0.511)$. The mean CSE of cells on IS was slightly higher, with $50.5 \%$ ( $\pm 18.7 \%$ standard deviation (SD) ) compared to OS $(39.9 \pm 28.8 \%$ SD).

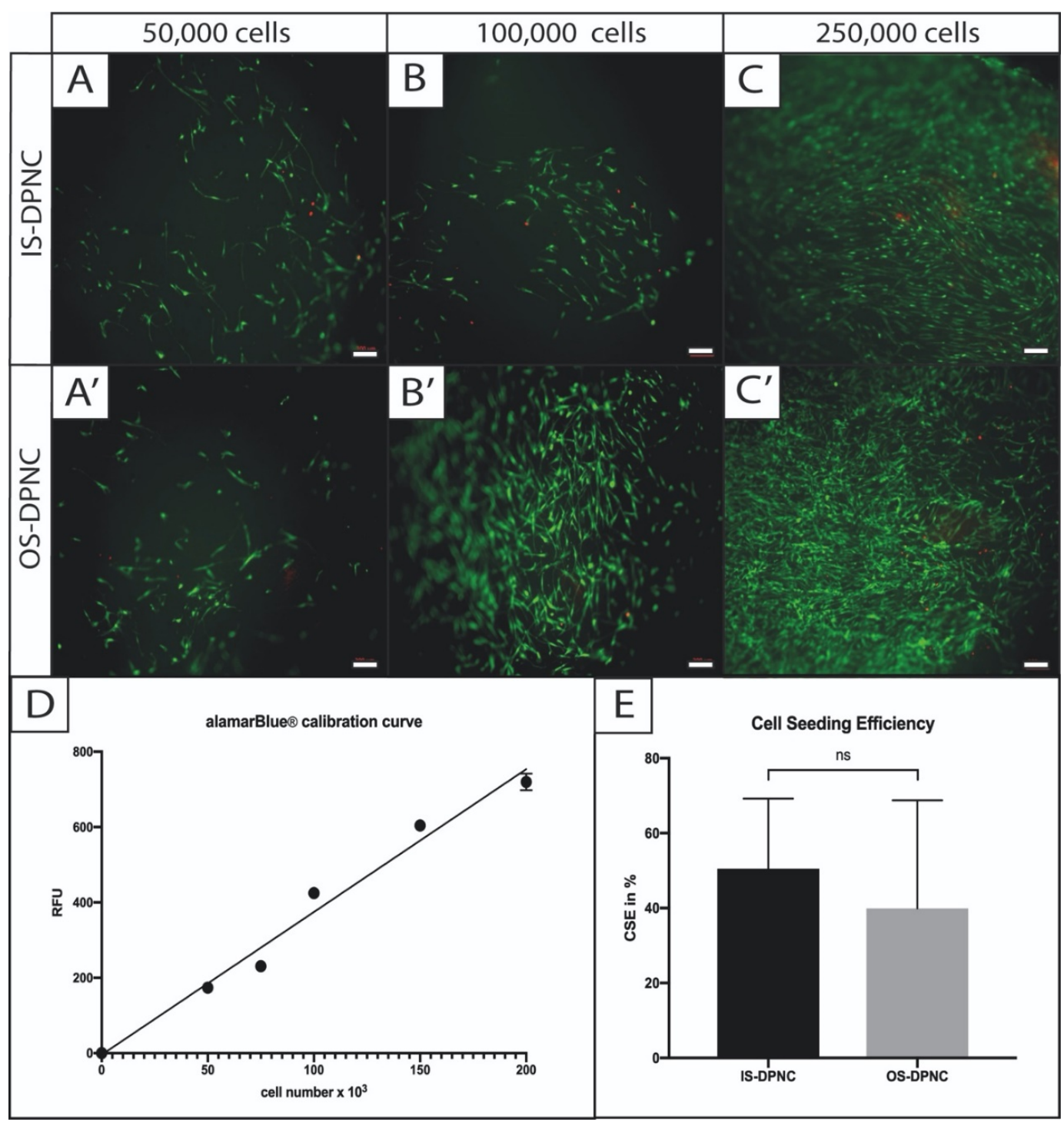

Figure 2. Cell seeding visualization and calculation of efficiency on different DPNC zones. ASCs were statically seeded in different concentrations on IS (A-C) or OS $\left(\mathbf{A}^{\prime}-\mathbf{C}^{\prime}\right)$ and were visualized by Live-Dead assay $4 \mathrm{~h}$ later. Vital cells were stained in green (FDA) and dead cells in red (PI). No difference in cell vitality was observed between DPNC zones and cell seeding concentration ( $\mathrm{bar}=200 \mu \mathrm{m}$ ). For the calculation of cell seeding efficiency, a calibration curve $\left(\mathrm{r}^{2}=0.98\right)$ was used to indirectly calculate the CSE through comparison with the MMA of defined cell numbers in 2D (D). CSE (E) revealed no significant difference $(p=0.3)$ between IS and OS ( $n=5$; ns = not significant; mean \pm SD). 


\subsection{ASC Metabolism and Proliferation}

To describe the zonal-dependent metabolic activity and proliferation capacity of ASCs, alamarBlue and PicoGreen assays were performed. ASCs exhibited a similar mitochondrial metabolic activity (MMA) in both DPNC zones. There was no significant difference regarding the aerobic aspiration between OS and IS during the first seven days of cell culture (Figure 3A). The increase in metabolic activity between days 3 and 7 was significant in both IS and OS $(p=0.004)$. PicoGreen assay monitoring proliferation showed a relative increase in DNA on both DPNC surfaces over the time period of 28 days $(p=0.017)$ (Figure 3B). The increase in DNA content was significantly higher on OS compared to IS after $14(p=0.0481)$ and 28 days $(p=0.0297)$.

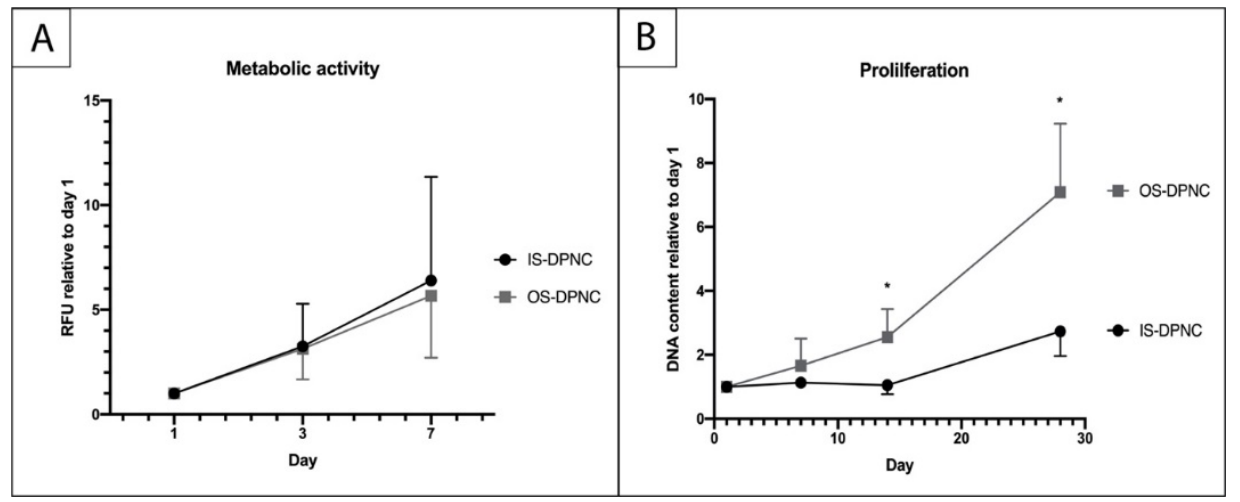

Figure 3. Evaluation of ASC metabolic activity and proliferation on DPNC zones. DPNC zones were seeded with $5 \times 10^{3}$ cells and cultured for $24 \mathrm{~h}$ until the first time of measurement of the metabolic activity in an alamarBlue assay (A) and proliferation in PicoGreen assay (B). The relative increase in MMA of ASCs was significant over time $(p=0.004)$ and similar on both DPNC zones $(\mathrm{n}=5)$. The DNA content of ASCs increased significantly on OS-DPNC in comparison to IS-DPNC after 14 and 28 days of culture, indicating that ASC proliferate more on OS-DPNC ( $\mathrm{n}=3{ }^{*} p<0.05 ;$ mean \pm SD).

\subsection{Biochemical Analysis of ASC Chondrogenesis}

To assess the production of sulfated GAGs (sGAGs) within the scaffold zones, a 1,9-dimethylmethylene blue (DMMB) assay was performed after 1, 7, 14 and 28 days (Figure 4). There was no increase in sGAGs in the standard culture medium, neither on IS nor OS (Figure 4A), whereas a significant increase in sGAGs in the chondrogenic induction medium was observed for both surfaces over time $(p<0.05)$ (Figure $4 \mathrm{~B})$. Moreover, the sGAG production at 28 days was significantly higher $(p=0.0105)$ on the IS than on the OS of DPNC (Figure 4B).

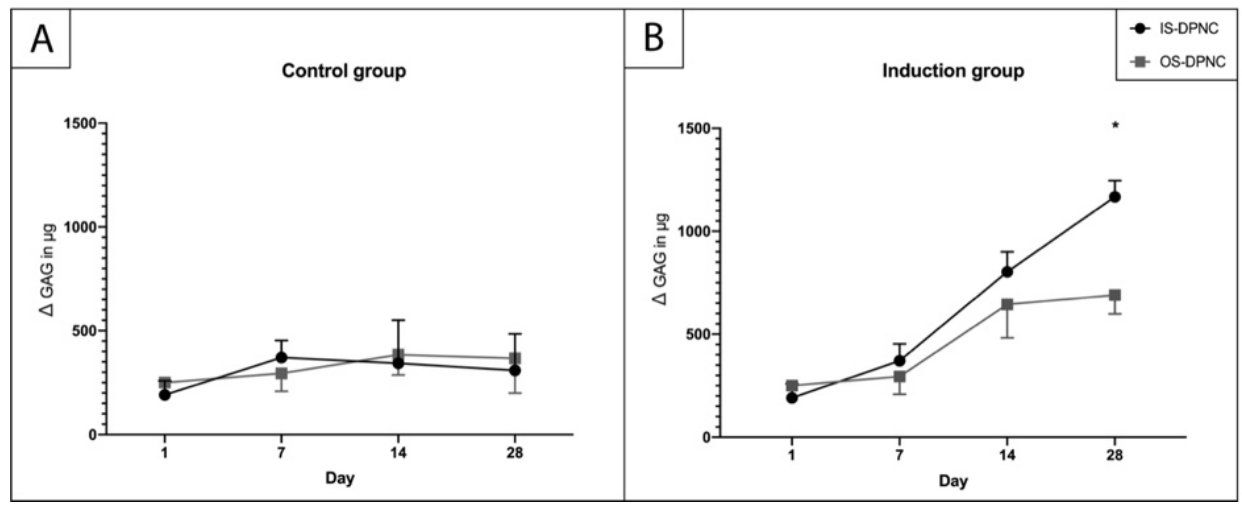

Figure 4. Quantification of sGAGs using DMMB assay. No increase in sGAG production occurred in control group (A) during the culture period. (B) A significantly higher $(p=0.0105)$ sGAG concentration was measured on IS compared to OS after 28 days of in vitro culture $\left(n=3 ;{ }^{*} p<0.05\right.$; mean \pm SD). 


\subsection{Histological Analysis and Cell Migration}

Phalloidin and $4^{\prime}$, 6-diamidino-2-phenylindole (DAPI) staining were performed to visualize cell migration through scaffolds and to observe potential morphological changes in ASCs. Cells seeded on the OS of DPNC formed stacked layers and grew around the scaffold, with only a minor infiltration into DPNC (Figure 5 $A^{\prime}-C^{\prime}$ ). In contrast, cells seeded on IS infiltrated the scaffold throughout the central and the intermediate matrix zones after 28 days of 3D-culture (Figure $5 \mathrm{~A}-\mathrm{C}$ ).

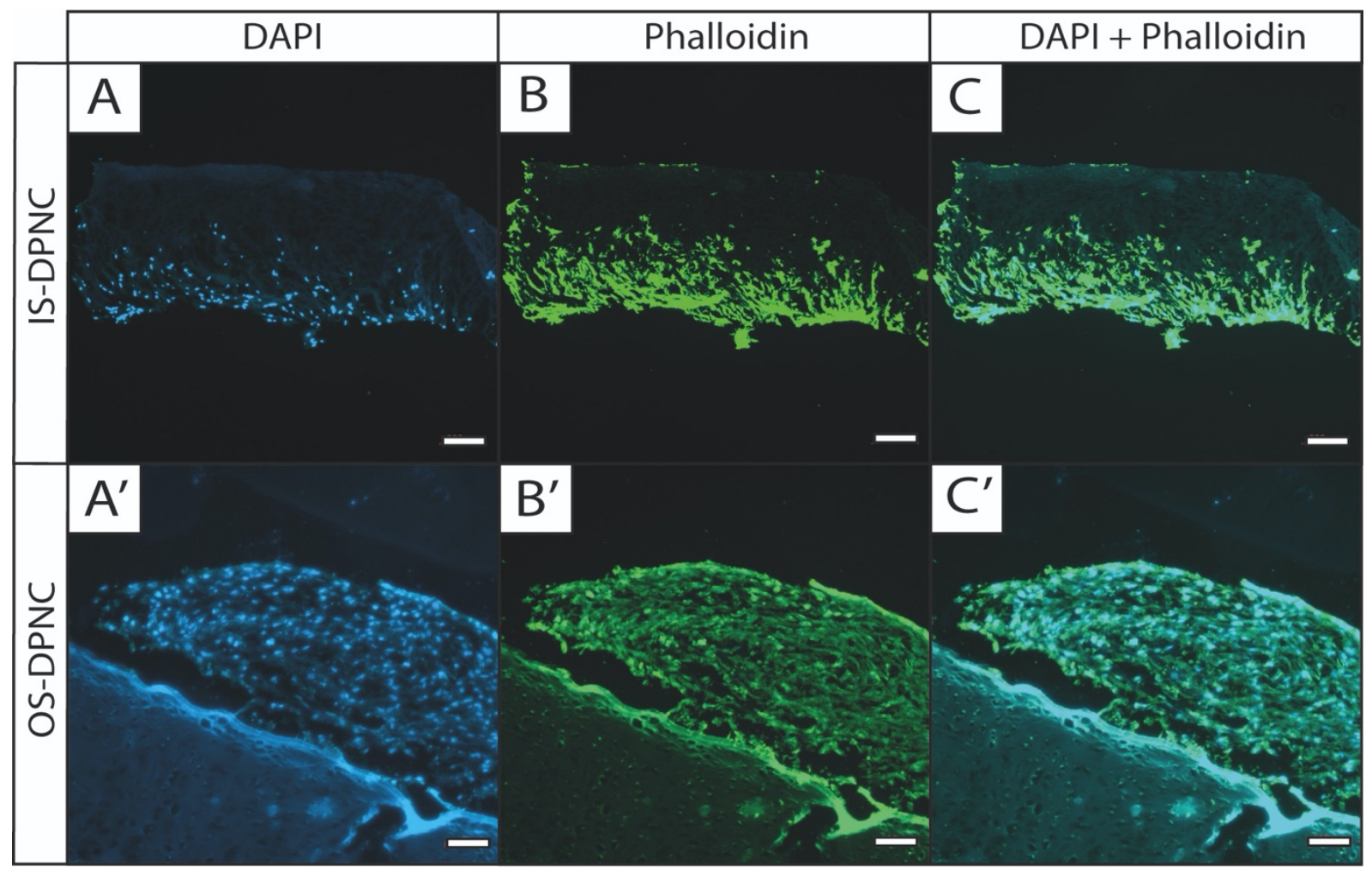

Figure 5. Fluorescence staining shows differences in growth pattern of ASCs between DPNC zones. DPNC scaffolds seeded with ASCs were cultured for 28 days, and were subjected to fluorescence staining with DAPI (blue, visualizes cell nucleus; $\mathbf{A}, \mathbf{A}^{\prime}$ ) and phalloidin (green, visualizes the actin cytoskeleton; B, $\left.\mathbf{B}^{\prime}\right)$. Right column $\left(\mathbf{C}, \mathbf{C}^{\prime}\right.$ ) shows overlaid images. ASCs seeded on IS clearly migrate into the scaffold $(\mathbf{A}-\mathbf{C}$, bar $=200 \mu \mathrm{m})$, whereas ASCs on OS form multilayer cell stacks on surface of scaffolds $\left(\mathbf{A}^{\prime}-\mathbf{C}^{\prime}\right.$, bar $\left.=100 \mu \mathrm{m}\right)(\mathrm{n}=3)$.

\subsection{Gene Expression Analysis}

A quantitative real-time polymerase chain reaction (qPCR) showed the expression of several chondrogenic markers in ASCs seeded and differentiated on the IS, as well as on the OS of the DPNC compared to the non-stimulated controls (Figure 6). Moreover, markers of chondrogenic differentiation were expressed differently on IS and OS. In particular, COL2A1 was expressed almost 10 -fold higher on OS compared to IS $(p<0.01)$ (Figure 6A). Similarly, SRY-related HMG-box 9 (SOX9), ACAN, collagen type 10 (COL10A1) and integrin alpha 10 (ITGA10) showed higher levels of expression on OS (Figure 6A-C). Only matrix metalloproteinase 13 (MMP13) was expressed approximately 2-fold higher on IS compared to OS $(p<0.0001)$ (Figure 6B). Interestingly, the fibrocartilage/fibroblast markers COL1A1 and ITGA11 were also significantly upregulated in OS-seeded cells compared to IS-seeded cells $(p<0.01)$ (Figure 6A,C). The expression of the peroxisome proliferator-activated receptor gamma (PPARG), a master regulator of adipocyte differentiation, is reduced in the chondrogenically-induced groups, indicating that there was no differentiation to adipose tissue. There was a significantly higher expression of proliferation marker Ki-67 (MKI67) on OS compared to IS $(p=0.0011)$ (Figure 6 C). 


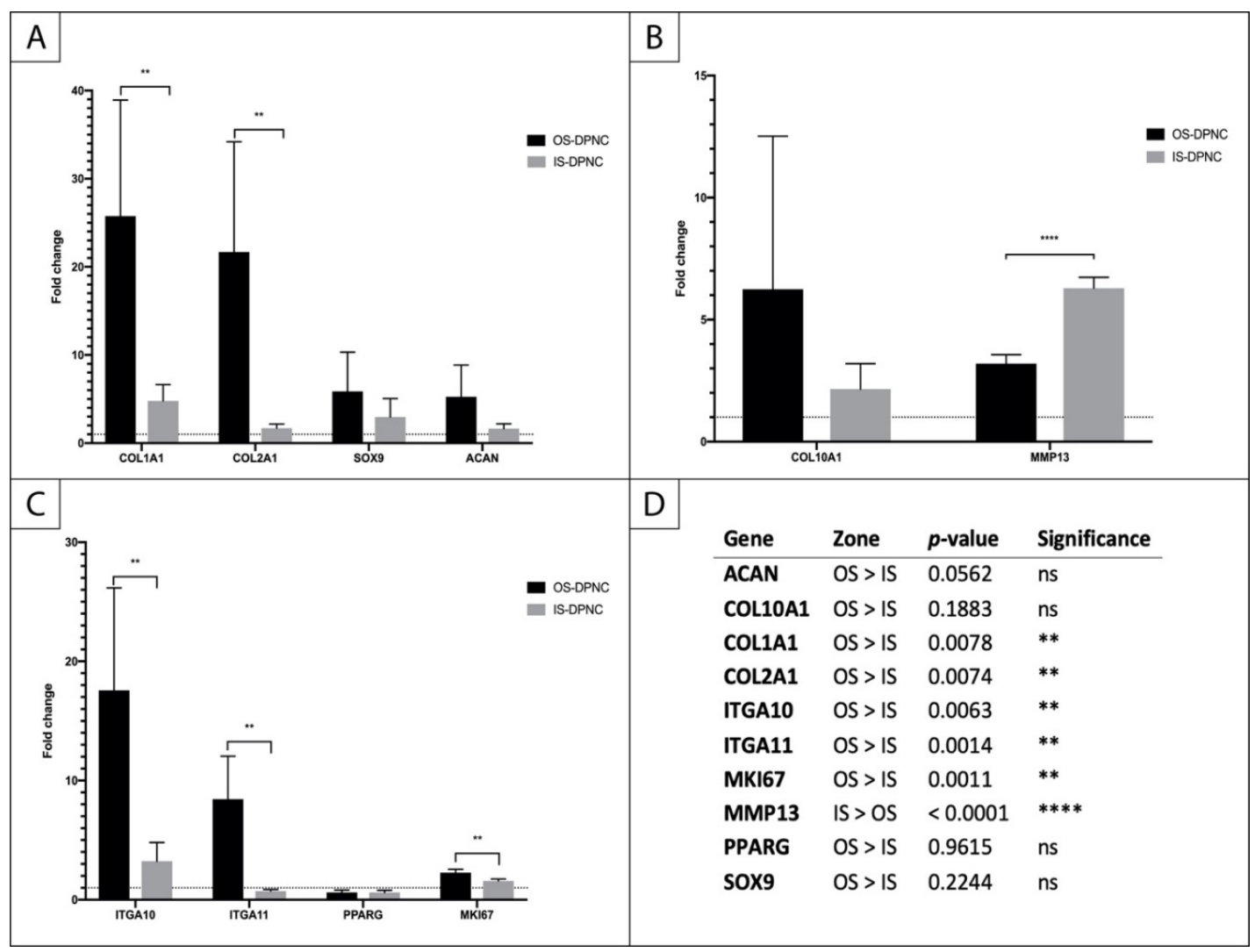

Figure 6. Relative changes in gene expression in ASCs seeded on IS and OS of DPNC. (A) early chondrogenic markers; (B) markers of chondrocyte hypertrophy; (C) integrins, adipogenesis and proliferation markers; (D) statistical analysis (n $=5 ;{ }^{* *} p<0.01 ; * * * * 0.0001$; mean $\left.\pm \mathrm{SD}\right)$.

\section{Discussion}

We investigated the interactions of decellularized porcine nasal cartilage with human ASCs, with a special focus on the effect of the zonal architecture of DPNC on the chondrogenic differentiation of ASCs. Previous experiments had already shown that DPNC is a conductive scaffold for human chondrocytes and is suitable for regenerating cartilage tissue. In this study, ASCs were selected as a stem cell source to investigate the influence of the cartilage ECM of the DPNC scaffold on the stem cell fate.

As the ECM provides not only a place to grow for stem cells but may also influence their cellular fate, we were looking for a suitable model to investigate the interactions of stem cells with human nasal cartilage. Several studies have previously described the zonal cellular architecture of human nasal cartilage [41-43]. However, it remains unclear whether this zonal organization reflects different cellular activities. It is tempting to speculate that the superficial (or peripheral) zone, with densely packed flat cells orienting parallel to the surface, represents an actively growing, proliferative area. In contrast, the central (or inner) zone, with longitudinally clustered, rounded chondrocytes, may be the site of maturation and hypertrophy, whereas the intermediate zone, with scattered oval cells, is the place where the cells switch from proliferation to differentiation. In the present study, we provided evidence that porcine nasal septal cartilage displays a zonal architecture, sGAG distribution and collagen type II distribution comparable to human septal cartilage. Thus, splitting DPNC through its central zone generates two compositionally and structurally distinct surfaces, the OS and IS, that could be used to test scaffold properties on mesenchymal stem cell behavior.

In this study, we recellularized the OS and IS surfaces of the DPNC with human ASCs and assessed their impact on cell vitality, metabolic activity and proliferation. The initial ASC vitality, MMA and CSE were not significantly influenced by the different ECM 
organization of OS or IS DPNC. These results demonstrate that the attachment of ASCs was comparable on both DPNC surfaces and suggest that further experiments were not affected by the seeding per se. The proliferation of ASCs were similar on both DPNC zones during the first week of the 3D culture. However, OS supported a higher proliferation rate at the second and third weeks of culture compared to IS. This observation was corroborated by the high mRNA expression level of the proliferation marker Ki-67 in ASCs seeded on OS. Histology and phalloidin staining revealed that ASCs were organized into layers on top of the OS, with only a minor infiltration into deeper zones, whereas on the IS side, the seeded cells migrated into the scaffold. As OS contains a higher density of collagen II fibrillar networks than IS, it is possible that the small pores at the OS prevent the efficient migration of the ASCs through the DPNC scaffold [43].

In our study we found that the early and midpoint chondrogenic differentiation markers, such as COL2A1 and ITGA10, were upregulated to multiple levels of fold change on OS upon chondrogenic induction [44]. The early chondrogenic differentiation of mesenchymal stem cells is a hybrid situation between proliferation and differentiation. Stem cells condensate and develop the flatter and more spindle-shaped phenotype of chondroprogenitors, whereas the mRNA expression of ECM-proteins (COL2A1, COL1A1, ACAN) and transcription factors (SOX9) are upregulated [22,45,46]. Prior studies revealed that COL1A1 is expressed in undifferentiated MSCs and that this marker indicates fibrocartilage formation or de-differentiation towards a fibroblast-like phenotype $[36,47,48]$. The relative expression of COL1A1 in ASCs on OS was elevated to a 25-times fold change. Additionally, ITGA11, which is more expressed in dedifferentiated than in differentiated chondrocytes, was also upregulated to high levels in ASCs cultured on OS [44,49]. These transcriptional changes were accompanied by a significantly lower GAG production in comparison to cells on IS, although an increased GAG synthesis was also observed on OS after chondrogenic induction when compared with control conditions.

Taken together, these results imply that the OS of DPNC guides ASCs towards cell proliferation, early chondrogenic differentiation and fibrocartilage formation. The ASCs on OS display a similar expression pattern that has been observed in chondroprogenitors, fibrocartilage and dedifferentiated chondrocytes $[36,47,48]$. Chondroprogenitors are the first step in chondrogenesis and characterized as a cell population that still has the potential to undergo adipogenesis and osteogenesis, whereas these features are progressively lost in more mature chondrocytes [50,51]. However, the upregulation of the hypertrophic chondrocyte marker COL10A1 indicates that OS-cultured ASCs are heterogenic in stem cell fate. We suggest that the cells display distinct differentiation and proliferation behavior depending on their exact location on OS. ASCs on the top of the stacked layers express fibroblast or fibrocartilage properties, whereas cells at the bottom of the stack interact with the OS ECM and are prone to chondrogenic differentiation. Further investigations of phenotypic markers expression in the OS cell layers are necessary to clarify this hypothesis. However, to create an adequate platform for cell-matrix interactions and allow for a more sufficient recellularization of the scaffold, we recommend increasing the porosity of OS for further trials.

In contrast to the appositional growth on OS, ASCs exhibited an infiltrating growth pattern if they were seeded on the IS of the DPNC. ASCs were able to migrate up to the intermediate zone of the DPNC. This invasive growth pattern was accompanied by a significantly higher sGAG production compared to OS $(p=0.038)$ upon chondrogenic induction for 28 days in a 3D culture. In accordance, mRNA levels of chondrogenic markers (ACAN, SOX9, COL2A1 and ITGA10) were elevated compared to the non-stimulated control, although those markers were not as highly expressed as those in cells on OS. An earlier study revealed that the gene expression of COL2A1 peaks at the beginning of the chondrogenesis of MSCs, and decreases during the progress of the differentiation to more advanced phenotypes; therefore, only a minor elevation of COL2A1 is not an exclusion criteria for chondrogenesis [48]. Furthermore, ITGA11 was not elevated in cells on IS, which indicates IS ASCs did not dedifferentiate towards fibroblast-like cells. Interestingly, 
the hypertrophic chondrocyte markers COL10A and MMP13 were also upregulated in IS-seeded ASCs. The MMP13 expression was significantly higher $(p<0.0001)$ on cells of IS compared to OS. Taken together, the upregulation of early and midpoint chondrogenic markers, expression of hypertrophy markers, significant sGAG production and central ECM invasion provides evidence that ASCs on IS adopt a chondrocyte behavior after 28 days of the 3D culture with the chondrogenic induction medium. As no increase in sGAG production could be observed in the control groups, the induction medium is still necessary for the chondrogenic differentiation of ASCs on any DPNC zone.

The main differences in the zones of the DPNC are the alignment of macromolecules and the three-dimensional ECM architecture [41,42]. Hypertrophic chondrocytes in IS leave large and round cavities behind after decellularization, whereas the cell niches in OS are significantly smaller, flatter, more numerous and arranged parallel to the surface [42,43]. It is well known that chondrocytes dedifferentiate in a monolayer cell culture, characterized by cell spreading and a switch from a chondrocyte gene expression profile to a fibroblastic gene expression pattern [52,53]. Zanetti et al. discovered in 1984 that inhibitors of actin polymerization reverse dedifferentiation by stimulating cell rounding, which eventually leads to redifferentiation [54]. The redifferentiation process is accompanied by the re-establishment of chondrogenic gene expression [55-57]. During chondrogenesis, cells condensate to spindle-shaped chondroprogenitors and mature over rounded chondroblasts to chondrocytes [57]. The round cell shape, thus, is linked to both the phenotype and differentiation status of chondrocytes [53,58-60] and the Rho A/ Rho-associated protein kinase $(R O C K)$-mediated actin cytoskeleton signaling pathway was identified as the mechanism behind this phenomena [61,62].

Besides 3D architecture, the DPNC also differs in ECM composition [42,43]. The different compositions of ECM ingredients are another explanation for different stem cell behavior within the zones. If the ingredients, rather than the 3D-structure of ECM zones, contribute to stem cell lineage fate, specific ECM-coated scaffolds could open new possibilities in tissue engineering. Indeed, such polymer/ECM composite grafts with a coculture of MSCs and chondrocytes showed a potential for cartilage regeneration [63]. However, Lu et al. demonstrated that regulatory changes towards the chondrogenesis of ASCs within a collagen type II scaffold were mainly induced through the downregulation of ROCK2 gene expression, leading to a round cell shape [62]. This observation may indicate that the most important differentiation cue is the change in cell morphology through the 3D structure of ECM ingredients, and not the ingredients themselves. Nevertheless, both mechanisms are a part of the complex interaction network between cells and the matrix, and further studies are required to fully understand the sequence and nature of events that guide chondrogenic differentiation.

We consider the results of this study to be highly relevant for further practical approaches in the tissue engineering of the DPNC. The properties of the native cartilage should be seen as the gold standard in cartilage tissue engineering [7]. However, the wide majority of efforts in tissue engineering with artificial polymer compounds have focused on creating a homogeneous tissue and neglect differences in the 3D structure and composition within the cartilage. Our results indicate that the stem cell fate differs significantly between ECM zones in the DPNC, and an interaction with a specialized ECM can be used to guide ASCs towards chondrogenesis. To achieve a high degree of biomimicry, zonaldependent differences should be considered and further investigated to provide more of an understanding of the cell-matrix interaction in order to improve the manufacturing of zonally organized, functional and native-like cartilage tissue. Based on the results of this study, a layer by layer approach that regards a zonal-dependent variation in pore size and morphology of the DPNC should be preferred in the 3D printing of artificial polymer compounds [10,64]. 


\section{Material and Methods \\ 4.1. Donors}

Fat tissues were collected from five heathy Caucasian female donors (mean age 54.8 years \pm 7.53 ) who underwent liposuction at the department of plastic surgery. After obtaining written informed consent, tissues were harvested with a waterjet-assisted liposuction system (Body Jet evo, human med AG, Schwerin, Germany) from the abdomen of the patients. All patients were non-smokers without significant medical history, and were tested negative for HIV and Hepatis B and C prior to surgery.

\subsection{Cell Isolation and Culture}

All tissue samples were transferred directly to the laboratory, and ASCs were isolated using $1 \mathrm{mg} / \mathrm{mL}$ collagenase (275 U/mg Collagenase Type II, Worthington Biochemical Corporation, Lakewood, NJ, USA) dissolved in Dulbecco's Modified Eagle Medium (DMEM, Thermo Fisher Scientific, Waltham, MA, USA) in $50 \mathrm{~mL}$ Falcon tubes. The lipoaspirate was incubated with collagenase solution on a three-dimensional shaker (TL 10, Edmund Buehler $\mathrm{GmbH}$, Bodelshausen, Germany) at $37^{\circ} \mathrm{C}$ for $10 \mathrm{~min}$, leading to phase separation. The upper phase was discarded and the process was repeated twice with the lower phase, which contains the stromal vascular fraction (SVF). DMEM was added to stop the enzymatic reaction, and the solution was passed through a $70 \mu \mathrm{m}$ cell strainer (Corning, NY, USA) into a fresh $50 \mathrm{~mL}$ Falcon (Sarstedt AG \& Co., Nuembrecht, Germany) and was centrifuged for $5 \mathrm{~min}$ at $500 \mathrm{~g}$. The pellet was resuspended in cell culture medium (DMEM + $10 \%$ fetal bovine serum (FBS, Sigma-Aldrich, St. Louis, MO, USA), $100 \mathrm{U} / \mathrm{mL}$ penicillin and $100 \mu \mathrm{g} / \mathrm{mL}$ streptomycin (Life Technologies, Carlsbad, CA, USA)) and the SVF was plated in a T-175 flask (Thermo Fisher Scientific, Waltham, MA, USA) and stored in a humidified $\left(21 \% \mathrm{O}_{2}, 5 \% \mathrm{CO}_{2}\right.$ and $37^{\circ} \mathrm{C}$ ) incubator (HERAcell 240i, Thermo Fisher Scientific, Waltham, MA, USA). On the next day, the flask was washed with phosphate-buffered saline (PBS, Life Technologies, Carlsbad, CA, USA) three times to remove remaining erythrocytes. The plastic-adherent ASCs were cultivated until $80 \%$ confluency, and were trypsinized, frozen and stored in liquid nitrogen until use. All ASCs were subjected to flow cytometry using positive mesenchymal stem cell markers and multilineage differentiation assays to prove their stem cell potential, as described previously [27]. The experiments were performed in triplicates, unless otherwise stated, with cells of passage 1 and 2.

\subsection{Manufacturing and Handling of DPNC}

DPNC was produced as published in the patent applications (Breiter et al., 2010) at the Institute of Bioprocess Engineering at the University of Erlangen in Germany. Briefly, the entire nasal septal cartilage was harvested from a pig belonging to the breed of Deutsches Edelschwein (Sus scrofa domestica). Cylindric discs (diameter $=5 \mathrm{~mm}$, height $=1 \mathrm{~mm}$ ) were taken from nasal septal cartilage and a chemical multistep decellularization process that included several washing steps, and treatments with $\mathrm{NaOH} \mathrm{H}_{2} \mathrm{O}_{2}$, a chaotropic salt and ethanol were performed to remove all chondrocytes, cell components and pathogens $[23,25]$. Decellularized scaffolds were stored in a dark and dry place until further usage.

\subsection{Histological and Immunohistochemical Analyses of Native porcine and Human Nasal Cartilage}

Porcine nasal samples were acquired and prepared as previously described. Human nasal cartilage were obtained from Science Care (Phoenix, AZ, USA) as fresh-frozen anatomical specimens. All human tissue donors involved gave informed consent to Science Care. All specimens were fixed in 3.5-3.7\% neutral buffered formaldehyde solution (Otto Fischar GmbH \& Co. KG, Saarbrücken, Germany), embedded in paraffin, sectioned at $4 \mu \mathrm{m}$ and stored at $56^{\circ} \mathrm{C}$ overnight. Staining was then performed with acidic alcian blue solution (Otto Fischar GmbH \& Co. KG, Saarbrücken, Germany), to detect sGAGs. For immunohistochemistry, deparaffinized and rehydrated sections were sequentially treated with $1 \%$ hyaluronidase (Sigma-Aldrich, St. Louis, MO, USA) in phosphate-buffered saline (PBS) and $0.2 \%$ pronase (Merck, Darmstadt, Germany) in PBS, each for $15 \mathrm{~min}$ at $37^{\circ} \mathrm{C}$. The 
collagen type II antibody (II-II6B3, Iowa City, IA, USA) was diluted 1:1000 and incubated $1 \mathrm{~h}$ at room temperature (RT), and the immunoreaction was detected by using the LSAB+ System-HRP (DAKO, Gloustrup, Denmark). Digital images were obtained by a Zeiss inverted light microscope (AxioObserver, Carl Zeiss, Jena, Germany).

\subsection{Static Seeding on Different DPNC Zones}

Scaffolds were sterilized and rehydrated before cell seeding as described by Schwarz et al. in a previous study [24]. The wet DPNC was lengthwise halved under sterile conditions using an anatomical forceps and a disposable scalpel (No. 20, FEATHER, Osaka, Japan). Directly after splitting the DPNC, the halves were transferred in a 24-well plate (Thermo Fisher Scientific, Waltham, MA, USA) that was coated with $0.27 \%$ agarose (Biozym LE, Hessisch Oldendorf, Germany) with either the OS or IS facing upwards. ASCs were seeded dropwise and concentrated in $50 \mu \mathrm{L}$ medium directly on either zone. After $2 \mathrm{~h}$ of seeding, $1.95 \mathrm{~mL}$ medium was added carefully to each well. The scaffolds were cultured under the same conditions as the cells in the monolayer culture, and medium was changed three times a week.

\subsection{Evaluation of Cell Vitality and Cell Seeding Efficiency (CSE)}

$4 \mathrm{~h}$ after seeding, a LD assay was performed to ensure seeding success, and to visualize cell distribution and vitality on different DPNC zones. For this purpose, scaffold zones were seeded directly with $5 \times 10^{4}, 1 \times 10^{5}$ or $2.5 \times 10^{5}$ ASCs and stained with LD staining solution containing $8 \mu \mathrm{g} / \mathrm{mL}$ fluorescein diacetate (FDA, Sigma Aldrich, St. Louis, MO, USA) and $20 \mu \mathrm{g} / \mathrm{mL}$ propidium iodide (PI, Sigma Aldrich, St. Louis, MO, USA) in serumfree DMEM for $5 \mathrm{~min}$ at $37^{\circ} \mathrm{C}$. Finally, pictures were taken with an inverted epifluorescence microscope (AxioObserver, Carl Zeiss, Jena, Germany).

CSE was calculated through the MMA of cells in a resazurin-based alamarBlue assay. Scaffold surfaces were seeded with $5 \times 10^{4}$ cells and incubated with culture medium. After $24 \mathrm{~h}$, the culture medium was replaced with alamarBlue working solution (alamarBlue cell viability reagent diluted 1:10 in DMEM, Thermo Fisher Scientific, Waltham, MA, USA) for $4 \mathrm{~h}$. A total of $100 \mu \mathrm{L}$ of each sample was transferred in a black-bottom 96-well plate (Corning, NY, USA) and the $590 \mathrm{~nm}$ emission wavelength was measured with a fluorescence absorbance microplate reader (Tecan SAFIRE II, Tecan Group, Maennedorf, Switzerland). AlamarBlue working solution was also added to an unseeded scaffold and was used as a blank. Relative fluorescence units (RFU) were calculated by analogously treated samples that were exposed to defined numbers of ASCs in monolayer cultures. Finally, CSE was calculated according to the following equation: CSE (\%) = RFU (DPNC sample)/RFU (cell number used for seeding).

\subsection{Influence of Matrix Zones on Metabolic Activity and Proliferation Capacity of ASCs}

To evaluate the long-term influence of different DPNC zones on the MMA and cell vitality, alamarBlue assay was performed as described above at 1,3 and 7 days after seeding. MMAs were then calculated relative to day 1 according to the following equation: RFU (day x)/RFU (day 1).

\subsection{Biochemical Analysis of Chondrogenic Differentiation}

DPNC zones (IS and OS) were seeded with $1 \times 10^{5}$ cells and cultured either in standard medium or in chondrogenic induction medium (StemMACS ChondroDiff Medium, Milteny Biotech, Bergisch Gladbach, Germany). PicoGreen assay was performed to quantify dsDNA concentration within the scaffold zones. A DMMB assay was used to quantify sGAG production, which was calculated by division of sGAG amount by scaffold wet weight. Results were corrected for sGAG concentration of corresponding empty scaffolds, resulting in $\triangle$ sGAG. Induction was started 7 days after seeding and scaffolds were harvested at 7,14 and 28 days, snap-frozen in liquid nitrogen and stored at $-80{ }^{\circ} \mathrm{C}$. Both assays were performed as described previously by the authors $[25,27,65]$. 


\subsection{Histological Analyses of DPNCs}

DPNCs were harvested 28 days after seeding and embedded into Tissue-Tek O.C.T. Compound (Sakura Finetec, Alphen aan den Rijn, The Netherlands) in a Tissue-Tek Cryomold $^{\circledR}$ (Sakura Finetec, Alphen aan den Rijn, The Netherlands) and stored at $-20^{\circ} \mathrm{C}$. Fourteen-nm-thick sections were made with a cryotome (CryoStar ${ }^{\mathrm{TM}}$ NX50 Cryostat, Thermo Fisher Scientific, Waltham, MA, USA) and were stored at $-20{ }^{\circ} \mathrm{C}$ until further processing. DAPI (D1306, Thermo Fisher Scientific, Waltham, MA, USA) and phalloidin (A12379, Alexa Fluor ${ }^{\mathrm{TM}} 488$ Phalloidin, Thermo Fisher Scientific, Waltham, MA, USA) staining were used to visualize the cell nuclei and cytoskeleton, respectively. Slides were washed with $0.1 \%$ Triton X-100 (Sigma Aldrich, St. Louis, MO, USA) for 5 min and stained with DAPI for $30 \mathrm{~s}$. Then the slides were washed in PBS and $50 \mu \mathrm{L}$ of phalloidin solution (diluted 1:400 in PBS) was added dropwise on the surface and incubated in the dark for another 20 min. After washing in PBS, slides were mounted with Fluoroshield ${ }^{\mathrm{TM}}$ ( $\mathrm{Ab}$ cam, Cambridge, UK) and a cover slip. Finally, pictures were taken with an inverted epifluorescence microscope (AxioObserver, Carl Zeiss, Jena, Germany).

\subsection{QPCR}

To detect and quantify relative changes in gene expression during chondrogenic differentiation, DPNC zones (IS and OS) were seeded in duplicates with $2.5 \times 10^{5}$ cells and cultured with chondrogenic induction medium or normal culture medium (control) for 28 days. Scaffolds were harvested in a $2 \mathrm{~mL}$ safe-seal Eppendorf tube (Eppendorf AG, Hamburg, Germany) and shock-frozen in liquid nitrogen. One $\mathrm{mL}$ Qiazol reagent (Qiagen, Venlo, The Netherlands) and a $7 \mathrm{~mm}$ steal bead (Qiagen, Venlo, The Netherlands) were added and the scaffolds were homogenized using mechanical lysis (Tissue Lyser LT, Qiagen, Venlo, The Netherlands) at $50 \mathrm{~Hz}$ for $3 \times 2 \mathrm{~min}$. The suspension was transferred into a fresh reaction tube and $200 \mu \mathrm{L}$ chloroform (Sigma Aldrich, St. Louis, MO, USA) were added. Tubes were centrifuged with $12,000 \mathrm{rpm}$ at $4{ }^{\circ} \mathrm{C}$ for $15 \mathrm{~min}$. The clear, aqueous upper phase was transferred to a fresh tube and 70\% ethanol was added in a ratio of 1:1. RNA was isolated and purified using the RNeasy Lipid Tissue Mini Kit (Qiagen, Venlo, The Netherlands) and cDNA was synthesized with the Transcriptor First Strand cDNA Synthesis Kit (Roche, Basel, Switzerland) according to the manufacturer's instructions. Then, qPCR was performed with innuMIX qPCR DSGreen Standard qPCR Kit (Analytik Jena, Jena, Germany) in a qTower3 G Touch (Analytik Jena, Jena, Germany). Primers (Eurofins Genomics, Ebersberg, Germany) are listed in Table 1. Amplification conditions were $95^{\circ} \mathrm{C}$ for $120 \mathrm{~s}, 90^{\circ} \mathrm{C}$ for $30 \mathrm{~s}$ and $60^{\circ} \mathrm{C}$ for $60 \mathrm{~s}$. Data were calculated by the $2^{-\Delta \Delta \mathrm{Ct}}$ method, using hypoxanthine phosphoribosyl transferase 1 (HPRT1) as housekeeping control gene, and were normalized to control values, which were arbitrarily set to be 1 . Calculations were performed using Excel (Microsoft, Redmond, WA, USA).

Table 1. Summary of target and housekeeping genes for qPCR. (nt = nucleotides, RefSeq = reference sequence).

\begin{tabular}{|c|c|c|c|c|}
\hline Gene & Primer (Left) & Primer (Right) & $\mathrm{Nt}$ & RefSeq \\
\hline \multicolumn{5}{|c|}{ Target Genes } \\
\hline$A C A N$ & cctcccettcacgtgtaaaa & gctccgcttctgtagtctgc & 64 & NM_001135.3 \\
\hline COL10A1 & caccttctgcactgctcatc & ggcagcatattctcagatgga & 104 & NM_000493.3 \\
\hline COL1A1 & ggattccctggacctaaag & ggaacacctcgctctcca & 63 & NM_000088.3 \\
\hline COL2A1 & gtgaacctggtgtctctggtc & tttccaggttttccagcttc & 94 & NM_001844.4 \\
\hline ITGA10 & cttttcctcgcacgtggt & gctccattccagtcataggc & 70 & NM_001004439.1 \\
\hline ITGA11 & cttttcctcgcacgtggt & gctccattccagtcataggc & 69 & NM_001004439.1 \\
\hline$M K I 67$ & ccaaccaaaagaaagtctctgg & tgatggttgaggctgttcct & 78 & NM_001145966.1 \\
\hline MMP13 & ccagtctccgaggagaaaca & aaaaacagctccgcatcaac & 85 & NM_002427.3 \\
\hline PPARG & tgacaggaaagacaacagacaaa & gaggactcagggtggttcag & 126 & NM_001330615.1 \\
\hline RUNX2 & cagtgacaccatgtcagcaa & gctcacgtcgctcattttg & 104 & NM_001015051.3 \\
\hline SOX9 & $\begin{array}{l}\text { gtacccgcacttgcacaac } \\
\text { Housekeeping Gene }\end{array}$ & tctcgctctcgttcagaagtc & 74 & NM_000346.3 \\
\hline HPRT1 & tgaccttgatttattttgcatacc & cgagcaagacgttcagtcct & 102 & NM_000194.3 \\
\hline
\end{tabular}




\subsection{Statistical Evaluation}

Statistical analysis was performed using GraphPad Prism v8 for Mac (GraphPad Software, San Diego, CA, USA). Gaussian distribution was evaluated using a ShapiroWilk-test. Depending on the distribution, either an unpaired $t$-test (student's test) or a Mann-Whitney U-test were used for statistical analysis. If more than two groups were evaluated, a two-way analysis of variance (ANOVA) approach was used. Sidak's multiple comparisons test was used as post-hoc analyses if results were significant. Results are presented as the mean \pm standard deviation (SD) and a $p$-value of $<0.05$ was regarded as statistically significant.

\section{Conclusions}

We have demonstrated that ASCs express different proliferation, invasion and chondrogenic differentiation behavior within different zones of the DPNC. OS significantly induced cell proliferation, but the dense collagen structure provided only minor cell invasion towards deeper layers. ASCs formed clusters on the surface and expressed a genetic upregulation of early chondrogenic differentiation and fibrocartilage markers. ASCs that were seeded on IS expressed an upregulation of chondrogenic- and hypertrophicdifferentiation-related markers, such as COL10A1 and MMP13, which was accompanied by a significantly higher sGAG production and higher scaffold invasion under the influence of a chondrogenic induction medium. Thus, this study provides the first evidence that the stem cell fate of ASCs can be additively guided through differences in the 3D architecture and ECM composition of nasal septal cartilage. We consider these results as highly relevant for further approaches in tissue engineering that aim to create a biomimetic, zonally-organized and native-like artificial cartilage replacement material.

Author Contributions: Conceptualization, C.K. and P.S.W.; methodology, C.K. and P.S.W.; validation, P.S.W., A.A. and T.L.S.; formal analysis, C.K., P.S.W. and A.A.; investigation, C.K. and P.S.W.; resources, T.L.S., A.A. and R.E.G.; data curation, C.K.; writing-original draft preparation, C.K. and P.S.W.; writing-review and editing, P.S.W., T.L.S., A.A. and R.E.G.; supervision, A.A., T.L.S. and R.E.G.; funding acquisition, P.S.W. and C.K. All authors have read and agreed to the published version of the manuscript.

Funding: This work was funded by FOEFOLE grant sponsored by the Ludwig Maximilians University of Munich to P.S.W and the research grant of the Hans-Meinecke-Stiftung (Hannover, Germany) sponsored to C.K.

Institutional Review Board Statement: The study was conducted according to the guidelines of the Declaration of Helsinki, and approved by the Institutional Ethics Committee ("Ethikkommission der medizinischen Fakultät") of Ludwig Maximilian University of Munich (Protocol number: 17-046).

Informed Consent Statement: Informed consent was obtained from all subjects involved in the study.

Acknowledgments: We acknowledge Alexandra Birt for technical assistance.

Conflicts of Interest: The authors declare no conflict of interest.

\section{References}

1. Mendez, B.M.; Thornton, J.F. Current basal and squamous cell skin cancer management. Plast. Reconstr. Surg. 2018, 142, 373E-387E. [CrossRef]

2. Vogt, P.M.; Gohritz, A.; Haubitz, M.; Steiert, A. Reconstruction of Nasal Deformity in Wegener's Granulomatosis: Contraindication or Benefit? Aesthet. Plast. Surg. 2011, 35, 156-161. [CrossRef]

3. Prasad, B.K.; Mokamati, S. Archives of Otolaryngology and Rhinology Tertiary Nasal Syphilis: Rare But Still a Reality. Arch. Otolaryngol. Rhinol. 2016, 2, 13-15. [CrossRef]

4. Rettinger, G. Risiken und Komplikationen der Rhinoplastik. Laryngo-Rhino-Otol. 2007, 86, 40-54. [CrossRef]

5. Rohrich, R.J.; Ahmad, J. A Practical Approach to Rhinoplasty. Plast. Reconstr. Surg. 2016, 137, 725e-746e. [CrossRef]

6. Ohara, K.; Nakamura, K.; Ohta, E. Chest wall deformities and thoracic scoliosis after costal cartilage graft harvesting. Plast. Reconstr. Surg. 1997, 99, 1030-1036. [CrossRef] [PubMed]

7. Lavernia, L.; Brown, W.E.; Wong, B.J.F.; Hu, J.C.; Athanasiou, K.A. Acta Biomaterialia Toward tissue-engineering of nasal cartilages. Acta Biomater. 2019, 88, 42-56. [CrossRef] [PubMed] 
8. Langer, R.; Vacanti, J. Advances in tissue engineering. J. Pediatr. Surg. 2016, 51, 8-12. [CrossRef] [PubMed]

9. Langer, R.; Vacanti, J.P. Tissue Engineering. Science 1993, 260, 920-926. [CrossRef] [PubMed]

10. Wiggenhauser, P.S.; Schantz, J.T.; Rotter, N. Cartilage engineering in reconstructive surgery: Auricular, nasal and tracheal engineering from a surgical perspective. Regen. Med. 2017, 12, 303-314. [CrossRef] [PubMed]

11. Palumbo, P.; Lombardi, F.; Siragusa, G.; Cifone, M.G.; Cinque, B.; Giuliani, M. Methods of isolation, characterization and expansion of human adipose-derived stem cells (ASCs): An overview. Int. J. Mol. Sci. 2018, 19, 1897. [CrossRef]

12. Bourin, P.; Bunnell, B.A.; Casteilla, L.; Dominici, M.; Katz, A.J.; March, K.L.; Redl, H.; Rubin, J.P.; Yoshimura, K.; Gimble, J.M. Stromal cells from the adipose tissue-derived stromal vascular fraction and culture expanded adipose tissue-derived stromal/stem cells: A joint statement of the International Federation for Adipose Therapeutics and Science (IFATS) and the International So. Cytotherapy 2013, 15, 641-648. [CrossRef]

13. Buschmann, J.; Gao, S.; Härter, L.; Hemmi, S.; Welti, M.; Werner, C.M.L.; Calcagni, M.; Cinelli, P.; Wanner, G.A. Yield and proliferation rate of adipose-derived stromal cells as a function of age, body mass index and harvest site-increasing the yield by use of adherent and supernatant fractions? Cytotherapy 2013, 15, 1098-1105. [CrossRef] [PubMed]

14. Im, G.I.; Ko, J.Y.; Lee, J.H. Chondrogenesis of adipose stem cells in a porous polymer scaffold: Influence of the pore size. Cell Transplant. 2012, 21, 2397-2405. [CrossRef] [PubMed]

15. Zuk, P.A. The Adipose-derived Stem Cell: Looking Back and Looking Ahead. Mol. Biol. Cell 2010, 21, 1783-1787. [CrossRef] [PubMed]

16. Wiggenhauser, P.S.; Kuhlmann, C.; Blum, J.; Giunta, R.E.; Schenck, T. Influence of software parameters on measurements in automatized image-based analysis of fat tissue histology. Acta Histochem. 2020, 122, 151537. [CrossRef] [PubMed]

17. Karkhaneh, A.; Naghizadeh, Z.; Shokrgozar, M.A.; Bonakdar, S.; Solouk, A.; Haghighipour, N. Effects of hydrostatic pressure on biosynthetic activity during chondrogenic differentiation of MSCs in hybrid scaffolds. Int. J. Artif. Organs 2014, 37, 142-148. [CrossRef]

18. Zhu, H.; Gong, H.; Liu, Q.; Chhen, H.H. Three-dimensional Bioprinting for Cartilage Regeneration. Tissue Eng. Nanotheranostics 2017, 49-74. [CrossRef]

19. Brizzi, M.F.; Tarone, G.; Defilippi, P. Extracellular matrix, integrins, and growth factors as tailors of the stem cell niche. Curr. Opin. Cell Biol. 2012, 24, 645-651. [CrossRef] [PubMed]

20. Jones, D.L.; Wagers, A.J. No place like home: Anatomy and function of the stem cell niche. Nat. Rev. Mol. Cell Biol. 2008, 9, 11-21. [CrossRef] [PubMed]

21. Guneta, V.; Zhou, Z.; Tan, N.S.; Sugii, S.; Wong, M.T.C.; Choong, C. Recellularization of decellularized adipose tissue-derived stem cells: Role of the cell-secreted extracellular matrix in cellular differentiation. Biomater. Sci. 2018, 6, 168-178. [CrossRef] [PubMed]

22. Vinatier, C.; Mrugala, D.; Jorgensen, C.; Guicheux, J.; Noël, D. Cartilage engineering: A crucial combination of cells, biomaterials and biofactors. Trends Biotechnol. 2009, 27, 307-314. [CrossRef] [PubMed]

23. Schwarz, S.; Koerber, L.; Elsaesser, A.F.; Goldberg-Bockhorn, E.; Seitz, A.M.; Dürselen, L.; Ignatius, A.; Walther, P.; Breiter, R.; Rotter, N. Decellularized Cartilage Matrix as a Novel Biomatrix for Cartilage Tissue-Engineering Applications. Tissue Eng. Part A 2012, 18, 2195-2209. [CrossRef]

24. Schwarz, S.; Elsaesser, A.F.; Koerber, L.; Goldberg-Bockhorn, E.; Seitz, A.M.; Bermueller, C.; Dürselen, L.; Ignatius, A.; Breiter, R.; Rotter, N. Processed xenogenic cartilage as innovative biomatrix for cartilage tissue engineering: Effects on chondrocyte differentiation and function. J. Tissue Eng. Regen. Med. 2015, 9, E239-E251. [CrossRef]

25. Elsaesser, A.F.; Bermueller, C.; Schwarz, S.; Koerber, L.; Breiter, R.; Rotter, N. In Vitro Cytotoxicity and In Vivo Effects of a Decellularized Xenogeneic Collagen Scaffold in Nasal Cartilage Repair. Tissue Eng. Part A 2014, 20, 1668-1678. [CrossRef] [PubMed]

26. von Bomhard, A.; Elsaesser, A.; Riepl, R.; Pippich, K.; Faust, J.; Schwarz, S.; Koerber, L.; Breiter, R.; Rotter, N. Cartilage regeneration using decellularized cartilage matrix: Long-term comparison of subcutaneous and intranasal placement in a rabbit model. J. Cranio-Maxillofac. Surg. 2019, 47, 682-694. [CrossRef]

27. Kuhlmann, C.; Schenck, T.L.; Tluczynski, K.; Aszodi, A.; Metzger, P.; Giunta, R.; Wiggenhauser, P.S. Experimental approach to nasal septal cartilage regeneration with adipose tissue-derived stem cells and decellularized porcine septal cartilage. Xenotransplantation 2020, 28, e12660. [CrossRef]

28. Lu, P.; Weaver, V.M.; Werb, Z. The extracellular matrix: A dynamic niche in cancer progression. J. Cell Biol. 2012, 196, 395-406. [CrossRef]

29. Egeblad, M.; Nakasone, E.S.; Werb, Z. Tumors as organs: Complex tissues that interface with the entire organism. Dev. Cell 2010, 18, 884-901. [CrossRef]

30. Gattazzo, F.; Urciuolo, A.; Bonaldo, P. Extracellular matrix: A dynamic microenvironment for stem cell niche. Biochim. Biophys. Acta-Gen. Subj. 2014, 1840, 2506-2519. [CrossRef]

31. Hynes, R.O. Extracellular matrix: Not just pretty fibrils Richard. Science 2009, 326, 1216-1219. [CrossRef]

32. Mammoto, T.; Ingber, D.E. Mechanical control of tissue and organ development. Development 2010, 137, 1407-1420. [CrossRef]

33. Folkman, J.; Moscona, A. Role of cell shape in growth control. Nature 1978, 273, 345-349. [CrossRef]

34. Ingber, D. Integrins As mechanochemical transducers. Curr. Opin. Cell Biol. 1991, 3, 841-848. [CrossRef] 
35. Von der Mark, K.; Gauss, V.; Von der Mark, H.; Müller, P. Relationship between shape and type of collagen synthesized as chondrocytes lose their cartilage phenotype in culture. Nature 1977, 270, 572. [CrossRef]

36. Schnabel, M.; Marlovits, S.; Eckhoff, G.; Fichtel, I.; Gotzen, L.; Vécsei, V.; Schlegel, J. Dedifferentiation-associated changes in morphology and gene expression in primary human articular chondrocytes in cell culture. Osteoarthr. Cartil. 2002, 10, 62-70. [CrossRef] [PubMed]

37. Caron, M.M.J.; Emans, P.J.; Coolsen, M.M.E.; Voss, L.; Surtel, D.A.M.; Cremers, A.; van Rhijn, L.W.; Welting, T.J.M. Redifferentiation of dedifferentiated human articular chondrocytes: Comparison of 2D and 3D cultures. Osteoarthr. Cartil. 2012, 20, 1170-1178. [CrossRef]

38. Khoshgoftar, M.; Torzilli, P.A.; Maher, S.A. Influence of the pericellular and extracellular matrix structural properties on chondrocyte mechanics. J. Orthop. Res. 2018, 36, 721-729. [CrossRef] [PubMed]

39. Guilak, F.; Nims, R.J.; Dicks, A.; Wu, C.L.; Meulenbelt, I. Osteoarthritis as a disease of the cartilage pericellular matrix. Matrix Biol. 2018, 71-72, 40-50. [CrossRef] [PubMed]

40. Alexopoulos, L.G.; Setton, L.A.; Guilak, F. The biomechanical role of the chondrocyte pericellular matrix in articular cartilage. Acta Biomater. 2005, 1, 317-325. [CrossRef]

41. Popko, M.; Bleys, R.L.A.W.; De Groot, J.W.; Huizing, E.H. Histological structure of the nasal cartilages and their perichondrial envelope. I. The septal and lobular cartilage. Rhinology 2007, 45, 148-152. [PubMed]

42. Homicz, M.R.; McGowan, K.B.; Lottman, L.M.; Beh, G.; Sah, R.L.; Watson, D. A compositional analysis of human nasal septal cartilage. Arch. Facial Plast. Surg. 2003, 5, 53-58. [CrossRef]

43. Wiggenhauser, P.S.; Schwarz, S.; Rotter, N. The distribution patterns of COMP and matrilin-3 in septal, alar and triangular cartilages of the human nose. Histochem. Cell Biol. 2018, 150, 291-300. [CrossRef] [PubMed]

44. Gouttenoire, J.; Bougault, C.; Aubert-Foucher, E.; Perrier, E.; Ronzière, M.C.; Sandell, L.; Lundgren-Akerlund, E.; Mallein-Gerin, F. BMP-2 and TGF- $\beta 1$ differentially control expression of type II procollagen and $\alpha 10$ and $\alpha 11$ integrins in mouse chondrocytes. Eur. J. Cell Biol. 2010, 89, 307-314. [CrossRef]

45. Bi, W.; Deng, J.M.; Zhang, Z.; Behringer, R.R.; De Crombrugghe, B. Sox9 is required for cartilage formation. Nat. Genet. 1999, 22, 85-89. [CrossRef]

46. Nakayama, N.; Pothiawala, A.; Lee, J.Y.; Matthias, N.; Umeda, K.; Ang, B.K.; Huard, J.; Huang, Y.; Sun, D. Human pluripotent stem cell-derived chondroprogenitors for cartilage tissue engineering. Cell. Mol. Life Sci. 2020, 77, 2543-2563. [CrossRef] [PubMed]

47. Barry, F.; Boynton, R.E.; Liu, B.; Murphy, J.M. Chondrogenic differentiation of mesenchymal stem cells from bone marrow: Differentiation-dependent gene expression of matrix components. Exp. Cell Res. 2001, 268, 189-200. [CrossRef] [PubMed]

48. Nguyen, L.H.; Kudva, A.K.; Guckert, N.L.; Linse, K.D.; Roy, K. Unique biomaterial compositions direct bone marrow stem cells into specific chondrocytic phenotypes corresponding to the various zones of articular cartilage. Biomaterials 2011, 32, 1327-1338. [CrossRef]

49. Varas, L.; Ohlsson, L.B.; Honeth, G.; Olsson, A.; Bengtsson, T.; Wiberg, C.; Bockermann, R.; Järnum, S.; Richter, J.; Pennington, D.; et al. $\alpha 10$ Integrin expression is up-regulated on fibroblast growth factor-2-treated mesenchymal stem cells with improved chondrogenic differentiation potential. Stem Cells Dev. 2007, 16, 965-978. [CrossRef]

50. Vinod, E.; Kachroo, U.; Amirtham, S.M.; Ramasamy, B.; Sathishkumar, S. Comparative analysis of fresh chondrocytes, cultured chondrocytes and chondroprogenitors derived from human articular cartilage. Acta Histochem. 2020, 122, 151462. [CrossRef]

51. Jayasuriya, C.T.; Chen, Q. Potential benefits and limitations of utilizing chondroprogenitors in cell-based cartilage therapy. Connect. Tissue Res. 2015, 56, 265-271. [CrossRef]

52. Holtzer, H.; Abbott, J.; Lash, J.; Holtzer, S. The Loss of Phenotypic Traits By Differentiated Cells in Vitro, I. Dedifferentiation of Cartilage Cells. Proc. Natl. Acad. Sci. USA 2006, 46, 1533-1542. [CrossRef]

53. Wuest, S.L.; Caliò, M.; Wernas, T.; Tanner, S.; Giger-Lange, C.; Wyss, F.; Ille, F.; Gantenbein, B.; Egli, M. Influence of mechanical unloading on articular chondrocyte dedifferentiation. Int. J. Mol. Sci. 2018, 19, 1289. [CrossRef]

54. Zanetti, N.C.; Solursh, M. Induction of chondrogenesis in limb mesenchymal cultures by disruption of the actin cytoskeleton. J. Cell Biol. 1984, 99, 115-123. [CrossRef] [PubMed]

55. Benya, P.D.; Shaffer, J.D. Dedifferentiated chondrocytes reexpress the differentiated collagen phenotype when cultured in agarose gels. Cell 1982, 30, 215-224. [CrossRef]

56. Benya, P.D.; Padilla, S.R. Dihydrocytochalasin B enhances transforming growth factor- $\beta$-induced reexpression of the differentiated chondrocyte phenotype without stimulation of collagen synthesis. Exp. Cell Res. 1993, 204, 268-277. [CrossRef] [PubMed]

57. Woods, A.; Wang, G.; Beier, F. Regulation of chondrocyte differentiation by the act in cytoskeleton and adhesive interactions. J. Cell. Physiol. 2007, 213, 1-8. [CrossRef]

58. Glowacki, J.; Trepman, E.; Folkman, J. Cell Shape and Phenotypic Expression in Chondrocytes. Exp. Biol. Med. 2013, 172, 93-98. [CrossRef] [PubMed]

59. Tekari, A.; Luginbuehl, R.; Hofstetter, W.; Egli, R.J. Chondrocytes expressing intracellular collagen type II enter the cell cycle and co-express collagen type i in monolayer culture. J. Orthop. Res. 2014, 32, 1503-1511. [CrossRef] [PubMed]

60. Barlič, A.; Drobnič, M.; Maličev, E.; Kregar-Velikonja, N. Quantitative analysis of gene expression in human articular chondrocytes assigned for autologous implantation. J. Orthop. Res. 2008, 26, 847-853. [CrossRef] 
61. Haudenschild, D.R.; Chen, J.; Pang, N.; Lotz, M.K.; D’Lima, D.D. Rho kinase-dependent activation of SOX9 in chondrocytes. Arthritis Rheum. 2010, 62, 191-200. [CrossRef]

62. Lu, Z.; Doulabi, B.Z.; Huang, C.; Bank, R.A.; Helder, M.N. Collagen type II enhances chondrogenesis in adipose tissue-derived stem cells by affecting cell shape. Tissue Eng.-Part A 2010, 16, 81-90. [CrossRef] [PubMed]

63. Levorson, E.J.; Hu, O.; Mountziaris, P.M.; Kasper, F.K.; Mikos, A.G. Cell-derived polymer/extracellular matrix composite scaffolds for cartilage regeneration, part 2: Construct devitalization and determination of chondroinductive capacity. Tissue Eng.-Part $C$ Methods 2014, 20, 358-372. [CrossRef] [PubMed]

64. Wise, J.K.; Yarin, A.L.; Megaridis, C.M.; Cho, M. Chondrogenic differentiation of human mesenchymal stem cells on oriented nanofibrous scaffolds: Engineering the superficial zone of articular cartilage. Tissue Eng.-Part A 2009, 15, 913-921. [CrossRef] [PubMed]

65. Barbosa, I.; Garcia, S.; Barbier-Chassefière, V.; Caruelle, J.P.; Martelly, I.; Papy-García, D. Improved and simple micro assay for sulfated glycosaminoglycans quantification in biological extracts and its use in skin and muscle tissue studies. Glycobiology 2003, 13, 647-653. [CrossRef] 